\title{
Gas Chromatographic-Mass Spectrometric Analysis of Volatiles Obtained by HS-SPME-GC-MS Technique from Aerial Parts of Ziziphora capitata L., and Evaluation for Biological Activity
}

\author{
MAJID MOHAMMADHOSSEINI ${ }^{1 *}$, ABOLFAZL AKBARZADEH ${ }^{2}$, \\ HAMID HASHEMI-MOGHADDAM ${ }^{3}$, MAHDIYEH SHAHNAMA ${ }^{1}$, \\ BIJAN FAHIMI ${ }^{4}$ and SOMAYEH AZAMI ${ }^{4}$
}

\author{
1Department of Chemistry, Shahrood Branch, Islamic Azad University, Shahrood, Iran. \\ 2Department of Medical Nanotechnology, Faculty of Advanced Medical Science, \\ Tabriz University of Medical Sciences, Tabriz, Iran. \\ ${ }^{3}$ Department of Chemistry, College of Basic Sciences, Damghan Branch, \\ Islamic Azad University, Damghan, Iran. \\ ${ }^{4}$ Department of Laboratory Sciences, Faculty of Medical Sciences, \\ Shahrood Branch, Islamic Azad University, Shahrood, Iran. \\ *Corresponding author E-mails: majidmohammadhosseini@yahoo.com
}

http://dx.doi.org/10.13005/ojc/320318

(Received: February 06, 2016; Accepted: March 30, 2016)

\begin{abstract}
Volatile constituent components from aerial parts of Ziziphora capitata L. were successfully separated using headspace solid-phase microextraction (HS-SPME) approach, and were subsequently analyzed by means of GC and GC-MS instruments. The major volatile compounds were found to be pulegone (23.8\%), p-mentha-3,8-diene (17.0\%), $\alpha$-pinene (11.4\%), $\beta$-pinene $(11.3 \%)$ and $p$-menth-3-en-8-ol (8.3\%) altogether involving more than $70 \%$ of the profile accounting for high frequency of monoterpene hydrocarbons. Moreover, the methanolic extracts of $Z$. capitata were evaluated for possible antioxidant and antibacterial activities. In this regard, antioxidant activity of the extracts was determined by monitoring the scavenging capability of the DPPH free radical. Antibacterial activity was evaluated against some of Gram-positive and Gram-negative bacteria using disc diffusion and broth microdilution methods. The minimum inhibitory concentration (MIC) and minimal bactericidal concentration (MBC) values varied over the ranges $3.12-12.5 \mathrm{mg} / \mathrm{ml}$ and $6.25-25 \mathrm{mg} / \mathrm{ml}$, respectively. Our study revealed that methanolic extracts of $Z$. capitata exhibit strong and promising broad-spectrum activities against all the test isolates. For clinical isolates, the minimal $\mathrm{MIC}$ and MBC values were related to $B$. cereus and $L$. monocytogenes strains, whereas for the standard strains, both $P$. aeruginosa and $S$. aureus showed the lowest MIC and MBC values under the same conditions.
\end{abstract}

Keywords: Ziziphora capitata, HS-SPME-GC-MS, methanolic extract, antioxidant activity, antibacterial activity. 


\section{INTRODUCTION}

The genus Ziziphora L. belongs to the Lamiaceae family from botanical point of view. The origins of these plants are mainly in Iraq, Turkey, Caucasia, Middle Asia, Afghanistan, Pakistan, Syria, Armenia, Anatolia, west Siberia and Turkmenistan. As shown in the dictionary of Iranian plant names, the genus Ziziphora comprises four endemic species, namely Z. clinopodioides, Z. capitata, Z. persica and $Z$. tenuior which can be found sporadically in different parts of Iran ${ }^{1,2}$. In local Persian tradition, Ziziphora capitata is called as "kakuti-e kuh" involving about nine subspecies all native to Iran. In Turkish folk medicine, there is a variety of promising medical applications for diverse species of Ziziphora plants worldwide. They are frequently prescribed as infusions for various purposes such as powerful aperitif, sedative, stomachic carminative and antiseptic agents ${ }^{3}$. Different species of Ziziphora are also used to treat gastrointestinal disorders, hypertension, fever, edema, heart disease, insomnia, lung disease and hemorrhoids in $\mathrm{China}^{4}$ and for wound healing in Turkey ${ }^{3}$.

According to the literature, some investigations are found including cytotoxic ${ }^{5}$, immunomodulatory $^{6}$, antimycotic ${ }^{7}$, antibacterial ${ }^{8,9}$ and antioxidant activities ${ }^{10-15}$ of essential oils and some extracts of plants belonging to the Ziziphora genus.

To the best of our knowledge, this is the first comprehensive report concerning the chemical profile obtained from volatile natural compounds present in the aerial parts of $Z$. capitata using the HS-SPME-GC-MS method. This study was followed by screening the phytochemical evaluations involving antioxidant and antibacterial activities of its methanolic extract.

\section{EXPERIMENTAL}

\section{Chemical and Supplies}

2,2'-diphenyl-1-picrylhydrazyl (DPPH), 2,6-di-tert-butyl-4-methylphenol (butylated hydroxytoluene) standard antioxidant agent (BHT), Gentamicin, Carbenciline, Ampicillin 10 (AMP10), Nalidixic acid (NA30), Nitrofurantoin (NFT 100) and Trimethoprim/ sulfamethoxazole (SXT) antibiotics were all provided from Sigma-Aldrich $\mathrm{GmbH}$ (Munich, Germany).

\section{Plant material and botanical identification}

The plant material was collected during the flowering stage in April 2014, in Sahraye Jalali, Shahrood region, Semnan Province, at an altitude of $4413 \mathrm{ft}(1345 \mathrm{~m})$ above sea level located at latitude $36^{\circ} 25^{\prime} \mathrm{N}$ and longitude $055^{\circ} 01^{\prime}$. A voucher specimen was deposited at the Herbarium (number 33895) of the Research Institute of Forests and Rangelands, Tehran, Iran.

\section{Preparation of the extracts}

The 100-gram portions including air-dried aerial parts of $Z$. capitata were first ground in a coffee grinder (Type 591, Moulinex, Paris, France) to produce a homogeneous powder. In order to obtain an identical particle size, the powder was passed through a sieve. To prepare the plant extract, 300 $\mathrm{ml}$ of methanol was added to the powder. To avoid light deterioration during extraction, the medium was completely covered with a thin layer of an aluminum foil. The system then placed on a shaker for $48 \mathrm{~h}$ under a mild rate at a mean frequency value of $50 \mathrm{rpm}$. In order to eliminate small suspended materials, the obtained solution was first passed through Whatman filters and was subsequently filtered through $45 \mu \mathrm{m}$ nylon filters in the next step. Finally, the resulting solution was decanted to the round-bottom flask of a rotary evaporator (RE, IKA RV 05 basic 1B, Staufen, Germany, D-79219) and the solvent was removed under a mild vacuum at $+35^{\circ} \mathrm{C}$. The extracts were stored under the darkness at $5^{\circ} \mathrm{C}$ until being used within a maximum period of one week.

\section{DPPH Radical Scavenging Activity (DPPH-RSA)}

The in vitro antioxidant activities of methanol extracts from the aerial parts of $Z$. capitata were evaluated using the DPPH reagent through their capability to scavenge the free radical DPPH following Nabavi et al. ${ }^{16}$, Gholivand et al. ${ }^{11}$ and some similar methods ${ }^{17-19}$ with slight modifications. In this study, to perform phytochemical evaluations, methanolic solutions of DPPH $\left(5 \times 10^{-4} \mathrm{M}\right)$ and $Z$. capitata extracts $(1000 \mu \mathrm{g} / \mathrm{ml})$ were first prepared. Further dilutions of the extracts were made to obtain the extracts concentrations over the overall range $12.5-1000 \mu \mathrm{g} / \mathrm{ml}$. Afterwards, the $3.00 \mathrm{ml}$ portions 
of each diluted extract solution were mixed with $1.00 \mathrm{ml}$ of DPPH, strongly shaken (vortex) and allowed to stand for $60 \mathrm{~min}$. for performance of possible reduction reaction under the darkness. When DPPH reacts with an antioxidant compound which can donate a hydrogen atom it is reduced 20. Finally, the absorbance of each solution was measured at $517 \mathrm{~nm}$ using a UVIKON-922 double beam UV/Vis spectrophotometer equipped with matched cuvettes. The experiments were repeated in triplicate, and the mean radical scavenging activity (RSA\%) values were considered for each sample. The same procedure was followed for the BHT and the corresponding RSA\% was calculated using the following formula (eqn.1).

$$
\operatorname{RSA}(\%)=\left[\left(A_{b}-A s\right) / A_{b}\right] \times 100
$$

Where $A_{b}$ and $A s$ respectively stand for absorption of blank sample (DPPH) and the absorption of tested extract solution. In addition, the blank solution involved all reagents except the extract.

\section{Antibacterial assay}

In this research, we used standard strains including Staphylococcus aureus (ATCC 25923), Escherichia coli (ATCC 25922), Pseudomonas aeruginosa (ATCC 27853) and Enterococcus faecalis (ATCC 29212) provided by Iran Medical Sciences University, Tehran, Iran. In addition, clinical isolates involving Staphylococcus epidermidis, Escherichia coli, Streptococcus agalactiae, Listeria monocytogenes, Proteus mirabilis, Salmonella typhi, Pseudomonas aeruginosa, Klebsiella pneumoniae and Bacillus cereus (from Imam Hussain hospital of Shahrood, Semnan Province and Iran University of Medical Sciences, Tehran, Iran) were used for the current study.

\section{Disc diffusion assay}

To determine the antibacterial activity of the extracts obtained from the aerial parts of $Z$. capitata, the disc diffusion assay was conducted according to the standard methods given by Clinical Laboratory Standard Institute recommendations $\mathrm{CLSI}^{21}$ and Scorzoni et al. ${ }^{22}$. Accordingly, in the first step, the microorganism suspensions containing $10^{8}$ colonyforming unit per $\mathrm{ml}(\mathrm{CFU} / \mathrm{ml})$ were loaded on a sterile cotton swabs and streaked over the dried surface of MHA plates for inoculation. Then, the sterile filter paper discs with $6 \mathrm{~mm}$ in diameter were impregnated with $20 \mu \mathrm{l}(2 \times 10 \mu \mathrm{l})$ of each sample $(100 \mathrm{mg} / \mathrm{ml})$ and were subsequently placed on the inoculated agar. In the next step, the plates were incubated at $37^{\circ} \mathrm{C}$ for $24 \mathrm{~h}$. Lastly, antibacterial activity was determined by measuring the diameter of inhibition zone against the microorganisms. The inhibition zone was measured in millimeters including the disc diameter. All of the tests were carried out in triplicate. Carbenciline $(100 \mu \mathrm{g} / \mathrm{ml})$ was used as the positive control. A disc which was impregnated with $20 \mu \mathrm{l}$ of solvent was used as the negative control. For this assay, the extracts of the $Z$. capitata species were dissolved in methanol.

\section{Minimum inhibitory concentration assay (MIC)}

The antibacterial activities of the extracts from aerial parts of $Z$. capitata were determined against Gram positive and Gram negative bacterial strains using broth microdilution method. The term MIC was evaluated on bacterial strains which showed sensitivity to the extracts in the disc diffusion assay according to the proposed methods by $\mathrm{CLSI}^{21}$, Weckesser et $a l^{23}$ and Mahdavi et al..$^{24}$ with some modifications. In order to determine the MIC, in a preliminary step, the 96-well plates ( $8 \times 12$ wells) were dispensed with $100 \mu$ l of the culture media (MHB) followed by charging the first well with $100 \mu \mathrm{l}$ of DMSO solution of the extract. Subsequent concentrations of the extract were prepared with serial dilution as follows: 100, 50, 25, 12.5, 6.25, $3.125,1.56$ and $0.78 \mathrm{mg} / \mathrm{ml}$. Afterwards, $100 \mu \mathrm{l}$ from each of their serial dilutions was transferred into consecutive wells. The inocula $(100 \mu \mathrm{l})$ containing $1-2 \times 10^{6} \mathrm{CFU} / \mathrm{ml}$ of each isolate were added to each well. The final volume in each well was $200 \mu$ l. The last well line of the plate was reserved to test the sterility control of the medium and inoculum viability. One well was used as negative control by filling 200 $\mu \mathrm{l}$ of MHB and the extract. E. coli ATCC 25922 and Gentamicin with concentrations of $50,25,12.5,6.25$, 3.12 and $1.56 \mu \mathrm{g} / \mathrm{ml}$ served as positive controls according to the CLSI recommendations ${ }^{21}$. All tests were carried out in triplicate. After incubation for 24 $\mathrm{h}$ at $37^{\circ} \mathrm{C}$, bacterial growth was evaluated by the presence of turbidity and a pellet on the well bottom. MIC was defined as the first well with no visible growth during an $18-20 \mathrm{~h}$ incubation period at $37^{\circ} \mathrm{C}$. After incubation time, $5 \mu$ l of the inoculations without 
growth were dispensed on MHA (Merck, Germany) plates and after $24 \mathrm{~h}$ incubation at $37^{\circ} \mathrm{C}$, the lowest concentration without visible growth was regarded as minimal bactericidal concentration (MBC) ${ }^{21}$.

\section{Gas chromatographic analyses}

Gas chromatographic analyses were performed on a Shimadzu 15A gas chromatograph equipped with a spilt/splitless (ratio 1:30) injector and a flame ionization detector, both operating at $250^{\circ} \mathrm{C}$. High purity nitrogen served as the carrier gas $(1 \mathrm{ml} / \mathrm{min}$ ) and the capillary column used was DB-5 (50 m×0.2 mm, film thickness $0.32 \mu \mathrm{m}$ ). The column temperature was kept at $60^{\circ} \mathrm{C}$ for $3 \mathrm{~min}$, then heated to $220^{\circ} \mathrm{C}$ with a $5^{\circ} \mathrm{C} / \mathrm{min}$ rate and finally kept constant at $220^{\circ} \mathrm{C}$ for $5 \mathrm{~min}$. relative percentage amounts were calculated from peak area using a CR5 Shimadzu CR pack without the use of correction factors.

Gas chromatographic mass spectrometric analysis was performed using a Hewlett-Packard 5973 instrument equipped with an HP-5MS column (30 m×0.25 mm, film thickness $0.25 \mu \mathrm{m}$ ). The effluent of the GC column was directly introduced into the source of MS. The column temperature programming was the same with GC analysis. The flow-rate of helium carrier gas was $1 \mathrm{ml} / \mathrm{min}$, final temperature $230^{\circ} \mathrm{C}$ while detector temperature was set at $250^{\circ} \mathrm{C}$; MS spectra were taken at $70 \mathrm{eV}(\mathrm{E} 1)$ over the range 30-350 amu with an electron multiplier voltage of $1800 \mathrm{eV}$ and scan time was 2 scans/ seconds.

\section{Headspace solid-phase microextraction method}

A commercially available manual SPME apparatus equipped with 75- $\mu \mathrm{m}$ diameter fibers obtained from Supelco (Bellefonte, USA) was used for the SPME procedure. Our routine SPME analysis is based on a modified syringe containing stainless steel microtubing within its syringe needle. This microtubing has an about 1-cm fused-silica fiber tip which is coated with an organic polymer involving polydimethylsiloxane combined with craboxene namely, PDMS-CAR. In fact, this fiber consists of porous particles of polydimethylsiloxane which are held together by carbowax as a powerful binder. The coated silica fiber can be moved between two positions, inside and outside the needle, with a plunger just like a normal syringe. Compared with a normal GC syringe, the diameter of the syringe needle housing the microtubing and coated silica fiber is not much increased. Before use, the fiber was conditioned at $250^{\circ} \mathrm{C}$ for $0.5 \mathrm{~h}$ in the $\mathrm{GC}$ injector. Then, one gram of powdered sample was placed in a $20-\mathrm{ml}$ sample vial sealed with septum-type caps provided from Supelco, which was heated for $15 \mathrm{~min}$ at $70^{\circ} \mathrm{C}$. After this time, the SPME needle pierced the septum, and the PDMS fiber was extended through the needle and exposed to the head-space above the sample for $15 \mathrm{~min}$ to trap the volatile compounds in the upper space of the vials. After an optimized extraction time (15 min), the fiber was drawn into the needle, and then the needle was removed from the septum and directly inserted onto the injection port of the GC. Desorption of analytes from the fiber coating was performed by heating the fiber in the splitless $\left(250^{\circ} \mathrm{C}\right)$ mode of injection port for $5 \mathrm{~min}$. Extraction and enrichment of the analyte are completed by the coating in the position outside the syringe needle. Penetration of the septum of a GC injection port was possible when the fiber was withdrawn into the syringe needle. Finally, desorption of the analyte and transfer to the capillary was performed after again moving the fiber to the position outside the syringe.

\section{Qualitative and quantitative analyses}

Identification and determination of the constituents of each profile were tentatively made by comparison of their mass spectral fragmentation patterns and retention indices $(\mathrm{RI})$ relative to $\mathrm{C}_{9}-\mathrm{C}_{25}$ $n$-alkanes both with those given in the literature ${ }^{25}$ as well as those stored in a MS spectral literature data. In addition, we utilized some of the spectral patterns as well as Kovatz indices based on previous findings of our research group ${ }^{26-53}$.

\section{RESULTS AND DISCUSSION}

\section{Chemical profile by HS-SPME technique}

Although the chemical profiles of hydrodistilled oils of $Z$. capitata have been reported previously, this study produced new profiles, mainly consisting of monoterpene hydrocarbons. Moreover, quantitative and qualitative analysis of volatile fractions from the aerial parts of $Z$. capitata, using the described method, has led to identification of several monoterpene hydrocarbons, oxygenated monoterpenes, sesquiterpene hydrocarbons and non-terpene hydrocarbons. To give a deeper insight into the separation process, the respective 
chromatogram has been represented in Figure 1. In addition, the names, retention indices and percentages of the constituents obtained from aerial parts of $Z$. capitata by the aforementioned method are listed in Table 1. As can be seen, there are negligible differences in numerical values of Kovats retention indices between the calculated ones and those cited in the literature. Furthermore, using the HS-SPME method, a total of 19 volatile components were identified from the aerial parts of $Z$. capitata totally accounting for $99.0 \%$ of the chemical profile (Table $1)$, including seven monoterpene hydrocarbons $(60.6 \%)$, seven oxygenated monoterpenes (35.1\%), two sesquiterpene hydrocarbons $(0.3 \%)$ and

Table 1: Chemical composition of the volatile constituents from the aerial parts of Ziziphora capitata obtained by HS-SPME approach ${ }^{\text {a }}$

\begin{tabular}{|c|c|c|c|c|c|c|}
\hline No. & Compound & Class & $\mathbf{R t}^{\mathrm{f}}$ & RI(Lit.) ${ }^{g}$ & RI (Cal.. $)^{\mathrm{h}}$ & Percentage (\%) \\
\hline 1 & 3-Methylcyclopentanone & $\mathrm{NH}$ & 4.92 & 848 & 854 & 0.2 \\
\hline 2 & $\alpha$-Pinene & $\mathrm{MH}$ & 6.69 & 932 & 940.6 & 11.4 \\
\hline 3 & Camphene & $\mathrm{MH}$ & 7.05 & 946 & 945.9 & 1.1 \\
\hline 4 & $\beta$-Pinene & $\mathrm{MH}$ & 7.61 & 979 & 982.2 & 11.3 \\
\hline 5 & Myrcene & $\mathrm{MH}$ & 7.92 & 991 & 996.2 & 1.9 \\
\hline 6 & Limonene & $\mathrm{MH}$ & 8.75 & 1029 & 1035.6 & 13.4 \\
\hline 7 & p-Mentha-3,8-diene & $\mathrm{MH}$ & 9.59 & 1030 & 1035.9 & 17.0 \\
\hline 8 & $(Z)-\beta$-ocimene & $\mathrm{MH}$ & 9.90 & 1032 & 1039.6 & 4.5 \\
\hline 9 & Isopentyl 2-methylbutanoate & $\mathrm{NH}$ & 10.2 & 1100 & 1103.3 & 0.3 \\
\hline 10 & $p$-Menth-3-en-8-ol & OM & 11.15 & 1150 & 1154.0 & 8.3 \\
\hline 11 & Menthofurane & OM & 11.44 & 1164 & 1169.1 & 0.5 \\
\hline 12 & Isopulegone & OM & 11.68 & 1177 & 1181.2 & 1.1 \\
\hline 13 & cis-Pulegol & OM & 12.40 & 1229 & 1219.6 & 1.0 \\
\hline 14 & 2-Methyoxythiophenol & $\mathrm{NH}$ & 12.45 & 1211 & 1212.8 & 2.5 \\
\hline 15 & Pulegone & OM & 12.92 & 1237 & 1244.8 & 23.8 \\
\hline 16 & $\gamma$-Terpineol & OM & 14.16 & 1199 & 1202.2 & 0.2 \\
\hline 17 & Piperitenone & OM & 14.72 & 1343 & 1347 & 0.2 \\
\hline 18 & $\alpha$-Copaene & $\mathrm{SH}$ & 15.23 & 1377 & 1374 & 0.2 \\
\hline \multirow[t]{10}{*}{19} & $\beta$-Bourbonene & $\mathrm{SH}$ & 15.39 & 1384 & 1386 & 0.1 \\
\hline & Total (\%) & & & & & 99.0 \\
\hline & $\mathrm{MH}^{\mathrm{b}}$ & \multicolumn{3}{|c|}{ Number } & & 7 \\
\hline & & \multicolumn{3}{|c|}{ Percentage (\%) } & & 60.6 \\
\hline & $\mathrm{OM}^{\mathrm{c}}$ & \multicolumn{3}{|c|}{ Number } & & 7 \\
\hline & & \multicolumn{3}{|c|}{ Percentage (\%) } & & 35.1 \\
\hline & $\mathrm{SH}^{\mathrm{d}}$ & \multicolumn{3}{|c|}{ Number } & & 2 \\
\hline & & \multicolumn{3}{|c|}{ Percentage (\%) } & & 0.3 \\
\hline & $\mathrm{NH}{ }^{e}$ & \multicolumn{3}{|c|}{ Number } & & 3 \\
\hline & & \multicolumn{3}{|c|}{ Percentage (\%) } & & 3.0 \\
\hline
\end{tabular}

a The compounds have been sorted according to their retention indices on an HP-5 MS capillary column

${ }^{\mathrm{b}}$ Monoterpene hydrocarbons

${ }^{c}$ Oxygenated monoterpenes

d Sesquiterpene hydrocarbons

e Nonterpene hydrocarbons

${ }^{\mathrm{f}}$ Retention time (min.)

${ }^{g}$ Kovatz retention indices given in the literature

${ }^{\mathrm{h}}$ Calculated Kovatz retention indices 
three non-terpene hydrocarbons (3.0\%). It should be noted that no oxygenated sesquiterpene was detected within the volatile chemical profile. Specifically, the major volatile components from the aerial parts were found to be pulegone $(23.8 \%)$, p-mentha-3,8-diene (17.0\%), $\alpha$-pinene (11.4\%), $\alpha$-pinene (11.3\%) and p-menth-3-en-8-ol (8.3\%). However, lower amounts of other natural compounds occurred in the profile including $(Z)$ - $\alpha$-ocimene (4.5\%), 2-methyoxythiophenol (2.5\%), myrcene
$(1.9 \%)$, isopulegone $(1.1 \%)$, camphene $(1.1 \%)$, cispulegol $(1.0 \%)$ and menthofurane $(0.5 \%)$. On the other hand, approximately trace amounts $(<0.5 \%)$ of 3-methylcyclopentanone $(0.2 \%), \gamma$-terpineol $(0.2 \%)$, piperitenone $(0.2 \%), \alpha$-copaene $(0.2 \%)$ and $\beta$-bourbonene $(0.1 \%)$ were recognized in the isolated volatile fractions from the aerial parts of $Z$. capitata. The details of molecular formulas and mass spectral patterns of the six dominant compounds found in the chemical profile of the volatile fraction in the

Table 2: Molecular formula and major mass fragments of the most abundant compounds in the volatile profile using HS-SPME technique

\begin{tabular}{|c|c|c|c|}
\hline \multicolumn{2}{|c|}{ No. Compound } & \multirow{2}{*}{$\begin{array}{c}\text { Molecular formula } \\
\mathrm{C}_{10} \mathrm{H}_{16} \mathrm{O}\end{array}$} & \multirow{2}{*}{$\begin{array}{l}\text { Mass fragments (m/z) } \\
81.1(100 \%)^{\text {a }} ; 152.05(82.87 \%) ; 67.10(67.36 \%) ; \\
109.10(54.67 \%) ; 82.10(35.61 \%)\end{array}$} \\
\hline 1 & Pulegone & & \\
\hline 2 & $p$-Mentha-3,8-diene & $\mathrm{C}_{10} \mathrm{H}_{16}$ & $\begin{array}{l}79.00 \text { (100\%); } 93.1(58.48 \%) ; 107.1(54.79 \%) \\
136.05(50.54 \%) ; 121.10(43.54 \%)\end{array}$ \\
\hline 3 & Limonene & $\mathrm{C}_{10} \mathrm{H}_{16}$ & $\begin{array}{l}68.1(100 \%) ; 93.10(99.98 \%) ; 67.10(76.72) \\
81.10(49.98 \%) ; 43.00(42.25 \%)\end{array}$ \\
\hline 4 & $\alpha$-Pinene & $\mathrm{C}_{10} \mathrm{H}_{16}$ & $\begin{array}{l}93.00 \text { (100\%); } 91.00 \text { (40.70\%); } 92.00 \text { (37.04\%); } \\
77.00 \text { (26.43\%); } 79.00 \text { (21.47\%) }\end{array}$ \\
\hline 5 & $\beta$-Pinene & $\mathrm{C}_{10} \mathrm{H}_{16}$ & $\begin{array}{l}93.10(100 \%) ; 91.00(28.04 \%) ; 69.10(24.72 \%) ; \\
77.00 \text { (22.74\%); } 79.00(22.22 \%)\end{array}$ \\
\hline 6 & p-Menth-3-en-8-ol & $\mathrm{C}_{10} \mathrm{H}_{18} \mathrm{O}$ & $\begin{array}{l}123.10(100 \%) ; 81.10(88.15 \%) ; 67.10(29.84 \%) ; \\
41.00(25.45 \%) ; 55.00(21.10 \%)\end{array}$ \\
\hline
\end{tabular}

aThe frequency of each fragment

Table 3: Radical scavenging activity (RSA\%) of $Z$. capitata and BHT against DPPH assay

\begin{tabular}{|c|c|c|c|c|c|}
\hline \multicolumn{3}{|c|}{ Methanolic extracts of $Z$. capitata } & \multicolumn{3}{|c|}{ BHT antioxidant agent } \\
\hline $\begin{array}{l}\text { Concentration } \\
\left(\mu \mathrm{g} \mathrm{ml}^{-1}\right)\end{array}$ & RSA(\%) & $\begin{array}{c}\mathrm{IC}_{50} \\
\left(\mu \mathrm{g} \mathrm{m \textrm { } \mathrm { m } ^ { - 1 }}\right)\end{array}$ & $\begin{array}{c}\text { Concentration } \\
(p p m)\end{array}$ & RSA(\%) & $\begin{array}{c}\mathrm{IC}_{50} \\
\left(\mu \mathrm{g} \mathrm{ml}^{-1}\right)\end{array}$ \\
\hline 50 & $36.1 \pm 0.1$ & & 12.5 & $50.6 \pm 1.2$ & \\
\hline 100 & $42 \pm 0.3$ & & 25 & $57.2 \pm 0.4$ & \\
\hline 250 & $53.8 \pm 0.2$ & $206.6 \pm 1.3$ & 50 & $68.9 \pm 0.9$ & $12.1 \pm 1.9$ \\
\hline 500 & $73.7 \pm 0.2$ & & 75 & $84.9 \pm 3.2$ & \\
\hline 750 & $96.9 \pm 0.2$ & & 100 & $97.5 \pm 0.8$ & \\
\hline \multicolumn{3}{|c|}{ Linear RSA(\%) equations: } & \multicolumn{3}{|c|}{ Linear RSA(\%) equations: } \\
\hline \multicolumn{3}{|c|}{ 1) $\mathrm{RSA} \%=0.0852 \mathrm{C}+32.487$} & \multicolumn{3}{|c|}{ 1) $\mathrm{RSA} \%=0.5898 \mathrm{C}+42.116$} \\
\hline \multicolumn{3}{|l|}{$\mathrm{R}^{2}=0.998$} & \multicolumn{3}{|l|}{$R^{2}=0.992$} \\
\hline \multicolumn{3}{|c|}{ 2) $\mathrm{RSA} \%=0.0847 \mathrm{C}+32.555$} & \multicolumn{3}{|c|}{ 2) $\mathrm{RSA} \%=0.47 \mathrm{C}+45.358$} \\
\hline \multicolumn{3}{|l|}{$\mathrm{R}^{2}=0.999$} & \multicolumn{3}{|c|}{$R^{2}=0.996$} \\
\hline \multicolumn{3}{|c|}{ 3) $\mathrm{RSA} \%=0.0851 \mathrm{C}+32.29$} & \multicolumn{3}{|c|}{ 3) $\mathrm{RSA} \%=0.5652 \mathrm{C}+42.704$} \\
\hline \multicolumn{3}{|l|}{$R^{2}=0.999$} & \multicolumn{3}{|l|}{$R^{2}=0.995$} \\
\hline
\end{tabular}


aerial parts of $Z$. capitata has been summarized in Table 2.

\section{Chemical composition of Z. capitata in similar reports}

To the best of our knowledge, this is the first report concerning the volatile fractions from the aerial parts of $Z$. capitata as one of the most important herbal plants. However, there have been several reports on the profiles of water-distilled essential oils from $Z$. capitata in different parts of Iran. In the work of Ebrahimi et al. ${ }^{54}$, in the hydrodistilled oil from aerial parts of $Z$. capitata growing wild in Sanandaj, Kurdistan Province, Iran at an altitude of $1850 \mathrm{~m}$, forty-two components were totally identified representing $98.1 \%$ of the oil mostly composed of sesquiterpene hydrocarbons $(46.9 \%)$ and oxygenated sesquiterpenes (24.8 $\%)$. In this report, the main constituents of the oil were germacrene D (21.3\%), limonene $(7.8 \%)$, $\beta$-caryophyllene (7.5\%), bicyclogermacrene (5.5\%) and spathulenol (4.5\%). In a similar report, Aghajani et al. Aghajani et a/, detected 19 components in the oil of $Z$. capitata, accounting for $98.8 \%$ of the total oil composition. This research revealed the major compounds of the oil respectively as germacrene $D(31.1 \%)$ and $(Z)-\beta$-ocimene $(15.4 \%)$ followed by $(E)-\beta$-ocimene (9.7\%), limonene $(7.8 \%)$, $\beta$-caryophyllene $(6.1 \%)$, hexadecanoic acid $(5.9 \%)$ and bicyclogermacrene (5.2\%). Accordingly, the chemical profile of the hydrodistilled oil of $Z$. capitata consisted of six monoterpene hydrocarbons (35.1\%), nine sesquiterpene hydrocarbons (49.4\%), three oxygenated sesquiterpenes (8.4\%) and only one aliphatic acid (5.9\%).

\section{Chemical composition of other species of Ziziphora genus in similar reports}

Schulz and co-workers" 55 have analyzed the essential oils obtained from various plant species belonging to a diverse set of genera involving Origanum, Satureja, Salvia, Sideritis, Thymus, Calamintha, Lavandula, Ziziphora and Thymbra by the use of two complementary methods, namely ATR/FT-IR and NIR-FT-Raman spectroscopy. This study showed characteristic key bands of the individual main volatile components such as carvacrol, thymol, p-cymene, $\gamma$-terpinene, camphor, 1,8-cineole, $\alpha$-pinene and $\beta$-pinene.

In addition, Konyalioglu and co-workers in 2006 reported the chemical composition of $Z$. taurica subsp. tauric and $Z$. taurica subsp. taurica essences, wherein they found that the former oil highly consisted of caryophyllene oxide (26.16\%), $\beta$-caryophyllene $(24.8 \%)$, and germacrene-D $(7.92 \%)$ while the latter one was mainly characterized by caryophyllene oxide $(26.16 \%)$, $\beta$-caryophyllene $(24.80 \%)$ and germacrene-D $(7.92 \%)^{56}$.

In the study of Bekhechi et al. ${ }^{57}$ on $Z$. hispanica (L.) essential oil from Algeria, the oil was characterized by a high content of pulegone (79.5\%), as well.

Table 4: The mean of the inhibition zones $(\mathrm{mm})$ using disk diffusion method

\begin{tabular}{|c|c|c|c|}
\hline \multirow[t]{2}{*}{ Bacteria } & \multirow[t]{2}{*}{ Antibiotics } & \multicolumn{2}{|c|}{ Inhibition zone (mm) } \\
\hline & & Obtained & Standard range $\mathrm{e}^{\mathrm{i}}$ \\
\hline Staphylococcus aureus a & - & $15 \pm 0.4 \mathrm{~g}$ & - \\
\hline Pseudomonas aeruginosa ${ }^{a}$ & - & N.S. ${ }^{h}$ & - \\
\hline Escheriscia coli a & - & N.S. & - \\
\hline \multirow[t]{4}{*}{ Escheriscia coli ATCC $25922^{\mathrm{b}}$} & $\mathrm{AMP}_{10}{ }^{\mathrm{c}}$ & 18 & $16-22$ \\
\hline & $\mathrm{NA}_{30}{ }^{10}$ & 25 & $23-28$ \\
\hline & $\mathrm{NFT}_{100}^{30} \mathrm{e}$ & 21 & $20-25$ \\
\hline & $\operatorname{SXT}^{100}$ & 26 & $23-29$ \\
\hline
\end{tabular}

a Clinical isolate ${ }^{b}$ Standard bacterial strainc Ampicillin $10\left(\mathrm{AMP}_{10}\right)$ antibiotic ${ }^{\mathrm{a}}$ Nalidixic acid $\left(\mathrm{NA}_{30}\right)$ antibiotic ${ }^{\mathrm{e}}$ Nitrofurantoin (NFT100) antibiotic ${ }^{f}$ Trimethoprim/sulfamethoxazole (SXT) antibiotic ${ }^{9}$ Relative standard deviations (RSD) based upon three replicate analysis. ${ }^{\text {h }}$ Not seen ' According to reference CLSI (2013) 
In a related study, Behravan et al. ${ }^{7}$ isolated the essential oils of $Z$. clinopodioides Lam. in Iran, and found pulegone $(44.5 \%)$, terpineol $(14.5 \%)$ methyl acetate $(10.9 \%)$, iso-neomenthol $(7.1 \%)$ and 1,8 -cineole $(4.1 \%)$ to be the most abundant compounds.

Amiri58 has reported, based on $\mathrm{GC}$ and GC-MS analyses, that the main components of water-distilled volatile oils from the aerial parts of $Z$. clinopodioides Lam. over the different growth stages were:

1. Pulegone (30.1\%), thymol (21.3\%), p-mentha3-en-8-ol (12.9\%) and piperitenone (9.3\%) in the pre-flowering stage.

2. Pulegone $(44.6 \%)$, p-mentha-3-en-8-ol (10.5\%), 1,8-cineole (10.4\%), piperitenone $(8.7 \%)$ and thymol $(6.7 \%)$ in the flowering stage.
3. Pulegone $(41.3 \%)$, isomenthone $(11.6 \%)$, p-mentha-3-en-8-ol (11\%), p-mentha-3,8diene $(7.2 \%)$ and thymol $(5.8 \%)$ in the postflowering stage.

Ding and coworkers ${ }^{59}$ have performed an interesting study concerning monitoring the changes in the chemical composition of Z. clinopodioides Lam. throughout nine different growth stages. This report highlighted pulegone (77.48-87.3\%), p-menthanone (2.79-12.39\%), trans-isopulegone (1.04-2.06\%), D-limonene (0.51-3.03\%) and eucarvone (1.5$4.48 \%$ ) as the most frequent compounds in the isolated essential oils.

Gholivand et al. ${ }^{11}$, have recently reported the main natural compounds occurring in the aerial parts of $Z$. tenuoir oil of the hydrodistilled essential oil using GC/MS technique. They have also compared

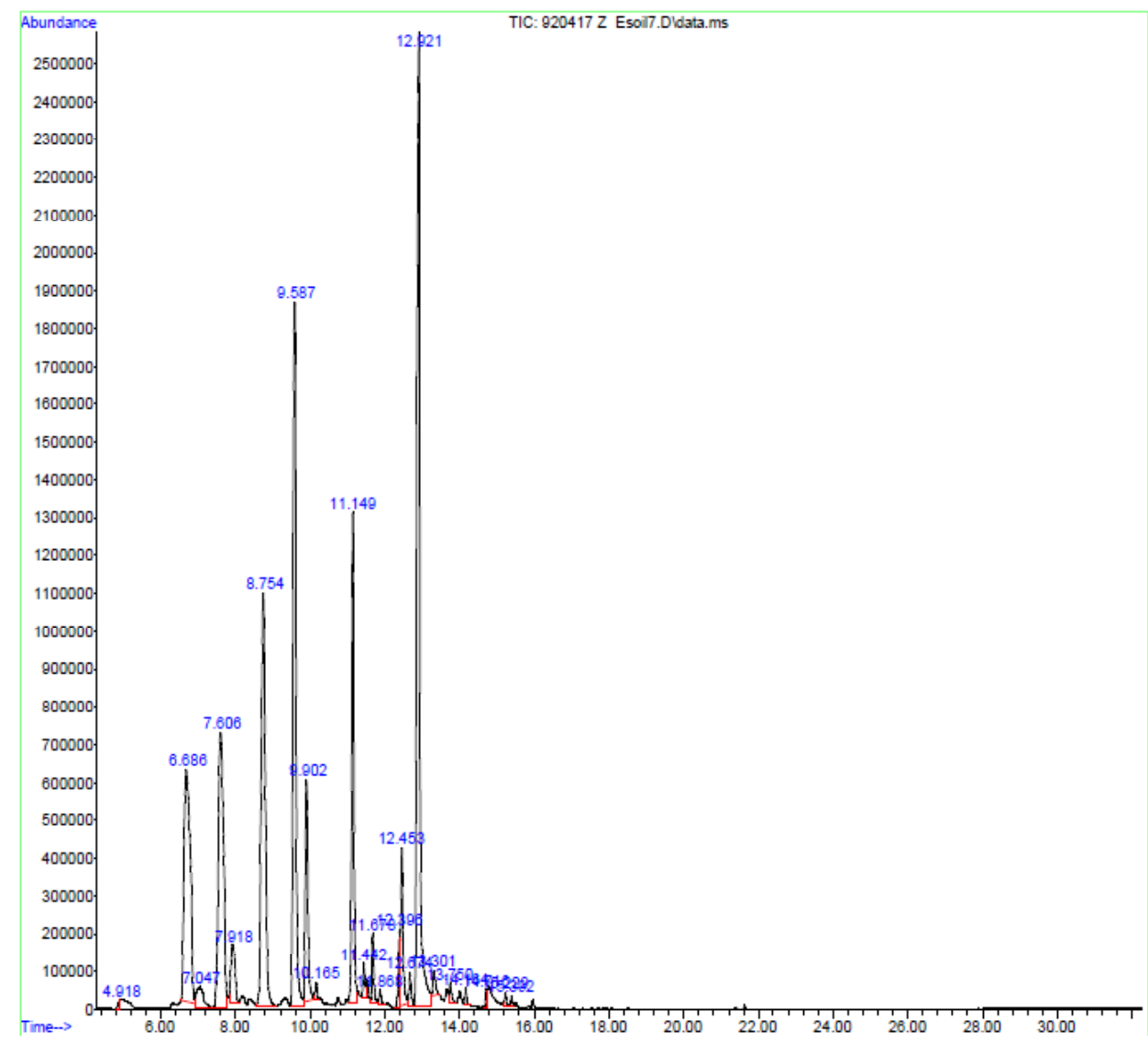

Fig. 1: The GC-MS chromatogram related to volatile profiles obtained from the aerial parts of Ziziphora capitata L. using headspace solid-phase microextraction (HS-SPME) approach 
the respective profiles in two stages of growth. In this research, the main constituents of the 28 identified compounds in the oil were found to be pulegone (67.34\% vs $59.61 \%$ ), $\beta$-humulene (3.24\% vs $3.25 \%$ ), and limonene (5.06\% vs $2.57 \%$ ) at the flowering and pre-flowering stages, respectively.

As mentioned above, numerous reports could be found in the literature in which the most frequency in all of the chemical profiles is related to oxygenated monoterpenes like pulegone and piperitenone ${ }^{3,60-65}$ with the exception of one report as an improved GC-MS analysis using multivariate curve resolution approach in which pulegone (38.3\%), isomenthone (7.06\%), limonene $(2.59 \%)$ along with some unusual compounds involving 3',5'-dihydroxyacetophenone (22.83\%), 2-methyl5-(1-methylethyl)-phenol (3.41\%) and 2-acetyl4,4-dimethyl-cyclopent-2-enone (2.49\%) constitute major natural compounds in the oil ${ }^{61}$.These findings altogether denote that the essential oils from different organs of various species of Ziziphora plants could be considered as potential sources of pulegone.

\section{Antioxidant activity}

The methanol extracts, which prepared from the aerial parts of $Z$. capitata, were subjected to screening for their possible antioxidant activity by the DPPH free radical scavenging assay. Considering corresponding regression analysis plots, the $Z$. capitata extract shows a rather desirable activity with an $\mathrm{IC}_{50}$ of $206.6 \pm 1.3 \mu \mathrm{g} / \mathrm{ml}$ (see Table 3). Moreover, BHT serves as a powerful antioxidant agent having an $\mathrm{IC}_{50}$ of $12.1 \pm 1.9 \mu \mathrm{g} / \mathrm{ml}$ under the same conditions. In other words as represented in Table 3, the DPPH radical scavenging abilities of all the methanolic extracts from the aerial parts of $Z$. capitata were considerably lower than that of the synthetic antioxidant BHT.

The term, $I C_{50}$ is defined as the concentration of an extract that is required for $50 \%$ inhibition in vitro of free radicals present in a medium. It is evident that a lower $\mathrm{IC}_{50}$ value implies for better DPPH radicalscavenging activity. Compared with similar reports, the obtained $\mathrm{IC}_{50}$ value for the extract of Z.capitata

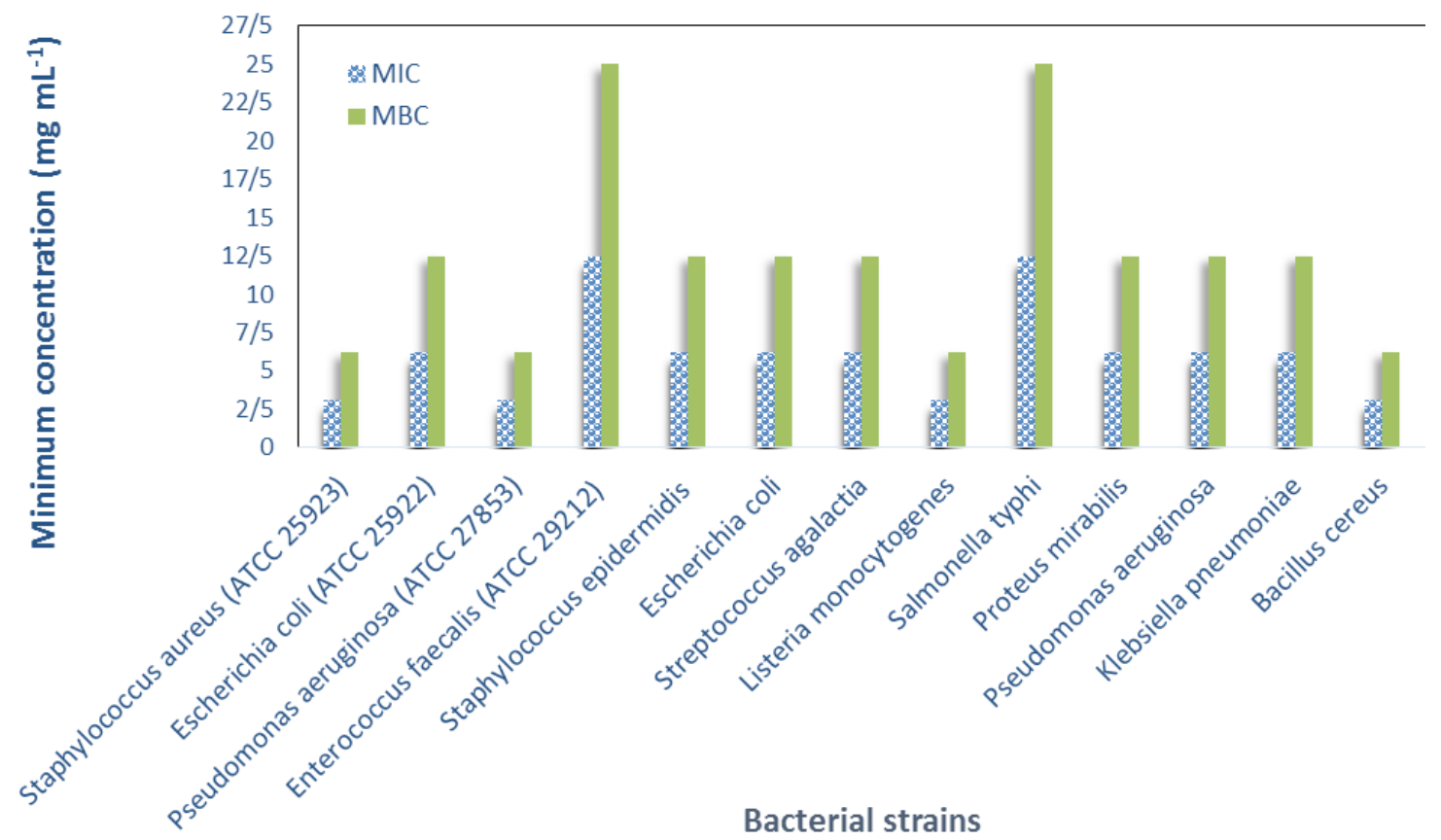

Fig. 2: Antibacterial activity of the methanolic extract from the aerial parts of Z. capitata against some of the bacterial strains involving nine clinical isolates + four standard strains (The RSD of all experiments fall within the range $0.1-0.9$ ) 
is better in some cases. These mainly include polar subfraction of $Z$. tenuoir extracts in preflowering stage $\left(\mathrm{IC}_{50}=284.12 \mu \mathrm{g} / \mathrm{ml}\right)^{11}$ as well as aqueous and methanol extracts of $Z$. tenuoir in which:

i) When treated with 1.5 and $1 \mathrm{mg} / \mathrm{l}$ of kin plus $0.1 \mathrm{mg} / \mathrm{l}$ of naphthalene acetic acid (NAA) results in $\mathrm{IC}_{50}$ values respectively as 0.307 and $0.369 \mathrm{mg} / \mathrm{ml}$.

ii) As growing wild plants respectively show $\mathrm{IC}_{50}=0.516$ and $9.229 \mathrm{mg} / \mathrm{ml}^{66}$.

However, our study on methanolic extract of Z. capitata showed higher $\mathrm{IC}_{50}$ value regarding some similar reports on some species of Ziziphora genus ${ }^{11}$, 12. In the work of Gholivand et al. ${ }^{11}$, the $\mathrm{IC}_{50}$ values for non-polar subfraction in the flowering stage, nonpolar subfraction in the preflowering stage and polar subfraction in the flowering stage of the $Z$. tenuoir extracts were found to be respectively as: $43.17 \pm$ $3.68,112.63 \pm 5.36$ and $135.21 \pm 6.78 \mu \mathrm{g} / \mathrm{ml}$.

\section{Antibacterial activity}

The antibacterial activity of the prepared extracts from the aerial parts of $Z$. capitata against Gram positive and Gram negative bacterial strains using the aforementioned disk diffusion and broth micro-dilution methods have been shown in Table 4 and Figure 2 for both standard strains and clinical isolates.

As seen in Table 4, using the disc diffusion method, an inhibition zone of $15 \pm 0.4 \mathrm{~mm}$ was obtained when using $S$. aureus while this test was found to be ineffective against $P$. aeruginosa and E. coli bacterial strains. Moreover, as shown in the Table 4, for bacterial strain of E. coli ATCC 25922, the obtained inhibition zones fall within the standard range (CLSI 2013) against all the antibiotics used.

It seems logical that the antibacterial activity of each extract is greatly influenced by the factors like its concentration, the family, genus, species of the plant of interest, the climatic conditions of the sampling area, and the polarity of the extracts solvent as well as the bacterial strains being used ${ }^{67}$.

The observed changes of MIC and MBC values as a function of the type of all bacterial strains in the extracts from the aerial parts of $Z$. capitata have been integrated in Figure 2. The perusal of this figure also demonstrates that the MIC values vary from 3.12 to $12.5 \mathrm{mg} / \mathrm{ml}$ while the MBC changes fall within the range $6.25-25 \mathrm{mg} / \mathrm{ml}$. As shown in Figure 2 , regarding the standard bacterial strains, the highest sensitivities are referred to $S$. aureus and $P$. aeruginosa which both possess the lowest MIC (3.12 $\mathrm{mg} / \mathrm{ml})$ and MBC $(6.25 \mathrm{mg} / \mathrm{ml})$ values. Compared to the other standard bacterial strains, the lowest sensitivity toward the extract of $Z$. capitata from its aerial parts was noted when $E$. faecalis was being used. In addition, a simple comparison revealed that the extract was so sensitive and effective against B. cereus and L. monocytogenes having MIC (3.12 $\mathrm{mg} / \mathrm{ml})$ and $\mathrm{MBC}(6.25 \mathrm{mg} / \mathrm{ml})$ values in the clinical strains. Furthermore, concerning the clinical isolates, the extract exhibited identical MIC and MBC values against E. coli, S. epidermidis, S. agalactia, P. mirabilis, P. aeruginosa and K. pneumoniae. However, the highest MIC and MBC values as the lowest sensitivity could be obtained when using $S$. typhi in the clinical isolates.

In conclusion, the methanolic extract from aerial parts of $Z$. capitata exhibited antibacterial activity against both Gram positive and Gram negative bacteria. The results of this study are partially in agreement with a previous study by Aghajani et al. ${ }^{8}$ which have reported the inhibitory effects of $Z$. capitata against microorganisms like E. coli PTCC 1330, S. aureus PTCC 1113, S. epidermidis PTCC 1349, S. typhi PTCC 1185 and P. aeruginosa PTCC 1310.

\section{CONCLUSION}

Medicinal plants are frequently used in the variety of approaches and play vital roles for human being. Quantification and qualification of the respective chemical profiles are of prime importance since there are broad spectra of natural compounds which can be used as proper alternatives for chemical drugs with noxious side effects ${ }^{68-71}$. Over the recent decades, there is a growing interest in drug discovery to medicinal plants for the maintenance of health in all parts of the world. In this report, the HS-SPME technique has been utilized to trap the volatile constituents from the aerial parts of Z. capitata when combined with gas chromatography and gas chromatography-mass spectrometry instrumentations. Polydimethylsiloxane-carboxene 
(PDMS-CAR) fiber was used as the solid phase for SPME-based analysis. The method enabled us to identify seven monoterpene hydrocarbons $(60.6 \%)$, seven oxygenated monoterpenes $(35.1 \%)$, two sesquiterpene hydrocarbons $(0.3 \%)$ and three non-terpene hydrocarbons (3.0\%). Since the $Z$. capitata extract may have a transferable hydrogen, it can reduce the DPPH reagent resulting in a color change from deep violet to yellow. The numerical values obtained for BHT and methanolic extract from the aerial parts of $Z$. capitata were found to be $206.6 \pm 1.3 \mu \mathrm{g} / \mathrm{ml}$ and $12.1 \pm 1.9 \mu \mathrm{g} / \mathrm{ml}$ respectively considering three replicate analyses under the same conditions.

In the other part of this work, the antibacterial activity of the extracts from aerial parts of $Z$. capitata was assessed against 13 microorganisms (4 standard strains + 9 clinical isolates) using the discdiffusion assay and micro-dilution methods followed by determination of the corresponding MIC and MBC values.
Regarding the obtained results, $Z$. capitata herbal plant could be considered as a novel source of oxygenated monoterpenes as one of the most important groups of natural products with potential antioxidative and antibacterial activities. Furthermore, finding new natural-based alternatives like medicinal plants having remarkable antibacterial activities is of paramount interest since they can be widely used as remedies against many infectious diseases.

\section{ACKNOWLEDGEMENT}

Financial and technical support from the Office for Research Affairs of the Islamic Azad University, Shahrood Branch and Islamic Azad University, Science and Research Campus are gratefully acknowledged.

\section{REFERENCES}

1. Mozaffarian, V. A Dictionary of Iranian Plant Names. Farhang Moaser Press, Iran, 1996.

2. Rechinger, K. H. Flora Iranica, No. 150. Akademische Druke-U. Verlagsanstalt,Wien, Austria, 1982.

3. Ozturk, S.; Ercisli, S. Food Control 2007, 18, 535-540.

4. Senejoux, F.; Girard, C.; Kerram, P.; Aisa, H. A.; Berthelot, A.; Bevalot, F.; Demougeot, C. J. Ethnopharmacol. 2010, 132, 268-273.

5. Ghazanfari, T.; Yaraee, R.; Shams, J.; Rahmati, B.; Radjabian, T.; Hakimzadeh, H. Food Agric. Immunol. 2013, 24, 1-7.

6. Azadmehr, A.; Latifi, R.; Mosalla, S.; Hajiaghaee, R.; Shahnazi, M. Daru J. Pharm. Sci. 2014, 22, 63.

7. Behravan, J.; Ramezani, M.; Hassanzadeh, M. K.; Eskandari, M.; Kasaian, J.; Sabeti, Z. J. Essent. Oil-Bear. Plants 2007, 10, 339-345.

8. Aghajani, Z.; Assadian, F.; Masoudi, S.; Chalabian, F.; Esmaeili, A.; TabatabaeiAnaraki, M.; Rustaiyan, A. Chem. Nat. Comp. 2008, 44, 387-389.

9. Ouzturk, S.; Ercisli, S. J. Ethnopharmacol.
2006, 106, 372-376.

10. Aliakbarlu, J.; Shameli, F. Turk. J. Biochem. 2013, 38, 425-431.

11. Gholivand, M. B.; Piryaei, M.; Maassoumi, S. M. Chin. J. Nat. Med. 2014, 12, 505-511.

12. Salehi, P.; Sonboli, A.; Eftekhar, F.; NejadEbrahimi, S.; Yousefzadi, M. Biol. Pharm. Bull. 2005, 28, 1892-1896.

13. Tian, S. G.; Shi, Y.; Zhou, X.Y.; Ge, L. A.; Upur, H. M. Pharmacogn. Mag. 2011, 7, 65-68.

14. Unal, E. L.; Mavi, A.; Kara, A. A.; Cakir, A.; Sengul, M.; Yildirim, A. Pharm. Biol. 2008, 46, 207-224.

15. Meral, G. E.; Konyalioglu, S.; Ozturk, B. Fitoterapia 2002, 73, 716-718.

16. Nabavi, S. F.; Ebrahimzadeh, M. A.; Nabavi, S. M.; Eslami, B. GRASAS ACEITES 2010, 61, 244-250.

17. Gupta, J.; Gupta, A. Oriental J. Chem. 2015, 31, 231-235.

18. Erbil, N.; Duzguner, V.; Durmuskahya, C.; Alan, Y. Oriental J. Chem. 2015, 31, 12631268.

19. Erbil, N.; Duzguner, V.; Durmuskahya, C.; Alan, Y. Oriental J. Chem. 2015, 31, 53-58. 
20. Onder, F. C.; Ay, M.; Sarker, S. D. J. Agric. Food. Chem. 2013, 61, 10498-10506.

21. CLSI, Clinical and Laboratory Standards Institute: Performance standards for antimicrobial susceptibility testing. 23th Information supplement, M100-S23; Wayne, PA: CLSI, 2013.

22. Scorzoni, L.; Benaducci, T.; Almeida, A. M. F.; Silva, D. H. S.; Bolzani, V. S.; MendesGiannini, M. J. S. J. Basic Appl. Pharm. Sci. 2007, 28, 25-34.

23. Weckesser, S.; Engel, K.; Simon-Haarhaus, B.; Wittmer, A.; Pelz, K.; Schempp, C. M. Phytomedicine 2007, 14, 508-516.

24. Mahdavi, B.; Yaacob, W. A.; Din, L. B.; Nazlina, I. Sains Malays 2012, 41, 1233-1237.

25. Adams, R. P. Identification of Essential Oil Components by Gas Chromatography/Mass Spectrometry. Allured Pubishing Co., Carol Stream, IL.: USA, 2007.

26. Akhlaghi, H.; Shafaghat, A.; Salimi, F.; Mohammadhosseini, M. Anal. Chem. Lett. 2011, 1, 325-327.

27. Mohammadhosseini, M.; Akbarzadeh, A.; Hashemi-Moghaddam, H.; Mohammadi Nafchi, A.; Mashayekhi, H. A.; Aryanpour, A. J. Essent. Oil-Bear. Plants 2016, 19.

28. Nekoei, M.; Mohammadhosseini, M. J. Essent. Oil-Bear. Plants 2016, 19.

29. Akhlaghi, H.;Asl, M.R.S.; Mohammadhosseini, M. Chem. Nat. Comp. 2009, 45, 448-449.

30. Akhlaghi, H.; Shafaghat, A.; Mohammadhosseini, M. J. Essent. Oil-Bear. Plants 2009, 12, 365-368.

31. Mohammadhosseini, M.; Beiranvand, M. J. Chem. Health Risks 2013, 3, 49-60.

32. Mohammadhosseini, M. Anal. Chem. Lett. 2013, 3, 226-248.

33. Mohammadhosseini, M. J. Chem. Health Risks 2014, 4, 75-95.

34. Mohammadhosseini, M.; Deeb, O.; AlaviGharabagh, A.; Nekoei, M. Anal. Chem. Lett. 2012, 2, 80-102.

35. Nekoei, M.; Mohammadhosseini, M. Anal. Chem. Lett. 2014, 4, 93-103.

36. Mohammadhosseini, M. Asian J. Chem. 2012, 24, 1432-1434.

37. Mohammadhosseini, M. Asian J. Chem. 2012 , 24, 3814-3820.

38. Mohammadhosseini, M. Asian J. Chem. 2013,
25, 390-392.

39. H a shem i-Mogh ad d a m, H. ; Mohammadhosseini, M.; Basiri, M. J. Essent. Oil-Bear. Plants 2015, 18, 884-893.

40. Mohammadhosseini, M. J. Essent. Oil-Bear. Plants 2015, 18, 1360-1371.

41. Mohammadhosseini, M.; Mahdavi, B.; Shahnama, M. J. Essent. Oil-Bear. Plants 2015, 18, 1321-1328.

42. Shahnama, M.;Azami, S.; Mohammadhosseini, M. Int. J. Curr. Microbiol. App. Sci 2015, 4, 275283.

43. Akhlaghi, H.; Nekoei, M.; Mohammadhosseini, M.; Motavalizadehkakhky, A. J. Essent. OilBear. Plants 2012, 15, 328-335.

44. Mohammadhosseini, M.; Pazoki, A.; Akhlaghi, H. Chem. Nat. Comp. 2008, 44, 127-128.

45. Mohammadhosseini, M.; Zamani, H. A.; Akhlaghi, H.; Nekoei, M. J. Essent. Oil-Bear. Plants 2011, 14, 559-573.

46. Mohammadhosseini, M.; Pazoki, A.; Zamani, H. A.; Akhlaghi, H. J. Essent. Oil-Bear. Plants 2011, 14, 101-105.

47. Nekoei, M.; Mohammadhosseini, M.; Akhlaghi, H. J. Essent. Oil-Bear. Plants 2012, 15, 926933.

48. Hashemi-Moghaddam, H. ; Mohammadhosseini, M.; Salar, M. Anal. Methods 2014, 6, 2572-2579.

49. Mohammadhosseini, M.; Nekoei, M. J. Essent. Oil-Bear. Plants 2014, 17, 747-757.

50. Mohammadhosseini, M.; Nekoei, M.; Mashayekhi, H. A.; Aboli, J. J. Essent. OilBear. Plants 2012, 15, $506-515$.

51. Motavalizadehkakhky, A. R.; Shafaghat, A.; Zamani, H. A.; Akhlaghi, H.; Mohammadhosseini, M.; Mehrzad, J.; Ebrahimi, Z. J. Med. Plants Res. 2013, 7, 1280-1292.

52. Mohammadhosseini, M.; Mahdavi, B.; Akhlaghi, H. J. Essent. Oil-Bear. Plants 2013, 16, 613-623.

53. Mohammadhosseini, M. J. Essent. Oil-Bear. Plants 2015, 18, 464-476.

54. Ebrahimi, S. N.; Hadian, J.; Sonboli, A. J. Essent. Oil-Bear. Plants 2009, 12, 678-682.

55. Schulz, H.; Ozkan, G.; Baranska, M.; Kruger, H.; Ozcan, M. Vib. Spectrosc 2005, 39, 249256.

56. Konyalioglu, S.; Ozturk, B.; Meral, G. E. 
Pharm. Biol. 2006, 44, 121-126.

57. Bekhechi, C.; Bekkara, F. A.; Abdelouahid, D. E.; Liu, K.; Casanova, J.; Tomi, F. J. Essent. Oil-Bear. Plants 2007, 10, 318-323.

58. Amiri, H. Nat. Prod. Res. 2009, 23, 601-606.

59. Ding, W. H.; Yang, T.; Liu, F.; Tian, S. G. Pharmacogn. Mag. 2014, 10, S1-S5.

60. Masrournia, M.; Shams, A. Asian J. Chem. 2013, 25, 6553-6556.

61. Pakniyat, E.; Mousavi, M. J. Chin. Chem. Soc. 2014, 61, 649-658.

62. Pirbalouti, A. G.; Amirkhosravi, A.; Bordbar F.; Hamedi, B. Chemija 2013, 24, 234-239.

63. Sharopov, F. S.; Setzer, W. N. Nat. Prod. Commun. 2011, 6, 695-698.

64. Sonboli, A.; Atri, M.; Shafiei, S. Chem. \& Biodiv. 2010, 7, 1784-1789.

65. Zhou, X. Y.; Yu, Q.; Gong, H. Y.; Tian, S. G. Nat. Prod. Commun. 2012, 7, 81-82.
66. Dakah, A.; Zaid, S.; Suleiman, M.; Abbas, S.; Wink, M. Saudi J. Biol. Sci. 2014, 21, 317323.

67. Khaled-Khodja, N.; Boulekbache-Makhlouf, L.; Madani, K. Ind. Crop Prod. 2014, 61, 4148.

68. Mohammadhosseini, M. A Comprehensive Review on New Methods for Processing, Separation and Identification of the Essential Oils. Islamic Azad University of Shahrood Press: Shahrood, Iran, 2016.

69. Rahimi, M.; Karimi, E.; Nekoei, M.; Mohammadhosseini, M. J. Essent. Oil-Bear. Plants 2016, 19, 307-320.

70. Nekoei, M.; Mohammadhosseini, M.; AlaviGharahbagh, A. J. Appl. Chem. 2009, 4, 3951.

71. Mohammadhosseini, M.; Akbarzadeh, A.; Shafaghat, A.; Hashemi-Moghaddam, H.; Mohammadi Nafchi, A.; Ashouri, H. J. Essent. Oil-Bear. Plants 2016, In press. 